\title{
Semi-Fixed Space Maintainer Treatment in Premature Loss Deciduous Tooth
}

\author{
Nabila Clara ${ }^{1}$, Jeffrey ${ }^{2^{*}}$ \\ ${ }^{1}$ Dentist Profession Education, Faculty of Medicine Jenderal Achmad Yani University, \\ Cimahi \\ 2 Department of Pediatric Dentistry, Dentistry Study Program, Faculty of Medicine Jenderal \\ Achmad Yani University, Cimahi, Indonesia - 40533 \\ *Correspondence: Jeffrey_dent2000@yahoo.com
}

\begin{abstract}
Introduction: The period of deciduous teeth is an important period in child development. Damage to deciduous teeth that occur and cannot be treated conservatively will cause premature decay of teeth which is often called premature loss. A space maintainer is a passive tool used to maintain dental arches due to premature loss of deciduous teeth. Case Report: An 11-year-old girl accompanied by her mother came to RSGMP Unjani in 2018 with complaints of lower right back teeth missing because they have removed. The patient's mother is worried that her replacement teeth will not grow properly. Intraoral examination revealed tooth loss 85. The study model was analyzed using the Moyers method. Results: Analysis of the lower jaw model showed excess space. Patients were treated with a semi-fixed band and loop space maintainer on teeth 85. Conclusion Eruption development problems due to premature loss can cause problems in the oral cavity, so mesial drifting needs to be prevented by applying a space management tool in the form of a semi-fixed band and loop space maintainer.
\end{abstract}

Keywords: premature loss; space management; space maintainer 


\title{
Perawatan Space Maintainer Semi Cekat Pada Kasus Premature Loss Gigi Sulung
}

\author{
Nabila Clara ${ }^{1}$, Jeffrey ${ }^{2^{*}}$ \\ ${ }^{1}$ Mahasiswa Kedokteran Gigi, Fakultas Kedokteran Universitas Jenderal Achmad \\ Yani, Cimahi \\ 2Departemen Kedokteran Gigi Anak, Fakultas Kedokteran Universitas Jenderal \\ Achmad Yani, Cimahi \\ *Koresponden: Jeffrey_dent2000@yahoo.com
}

\begin{abstract}
Abstrak
Pendahuluan: Periode gigi sulung merupakan periode yang penting dalam perkembangan anak. Kerusakan gigi sulung yang terjadi dan tidak dapat dirawat secara konservatif akan menyebabkan tanggalnya gigi sulung sebelum waktunya yang sering disebut premature loss. Space maintainer adalah alat pasif yang digunakan untuk mempertahankan lengkung gigi akibat premature loss gigi sulung. Laporan Kasus: Anak perempuan berusia 11 tahun ditemani ibunya datang ke RSGMP Unjani pada tahun 2018 dengan keluhan gigi belakang kanan bawah hilang karena dicabut. Ibu pasien khawatir gigi penggantinya tidak tumbuh dengan baik. Pemeriksaan intra oral menunjukkan kehilangan gigi 85. Model studi dianalisis dengan menggunakan metode Moyers. Hasil: Analisis model rahang bawah menunjukkan adanya kelebihan ruangan. Pasien dilakukan perawatan space maintainer semi cekat band and loop pada gigi 85. Simpulan: Gangguan perkembangan erupsi akibat premature loss dapat menimbulkan masalah didalam rongga mulut, sehingga mesial drifting perlu dicegah dengan mengaplikasikan alat space management berupa space maintainer semi cekat band and loop.
\end{abstract}

Kata kunci : premature loss; space management; space maintainer 


\section{Pendahuluan}

Perkembangan oklusi dari gigi sulung sering mengalami gangguan yang dapat memengaruhi hubungan oklusi gigi permanen. Periode gigi sulung merupakan periode yang penting dalam perkembangan anak, apabila terjadi kerusakan pada gigi sulung dan tidak dapat dirawat secara konservatif maka akan terjadi premature loss. ${ }^{1-4}$

Premature loss akan mengakibatkan kondisi kompleks pada rongga mulut anak, antara lain perubahan pertumbuhan oklusi, gigi permanen kekurangan tempat sebab pada masa tunggu erupsi gigi permanen terjadi pergeseran gigi posterior ke arah mesial, anak kesulitan untuk mengunyah makanan yang berdampak terjadinya kekurangan asupan nutrisi yang sangat dibutuhkan dalam proses tumbuh kembang anak. ${ }^{2}$

Gigi sulung yang mengalami premature loss harus segera ditangani dengan space management untuk mencegah terjadinya kelainan oklusi yang disebabkan kehilangan ruang. Space management terdiri dari space maintainer yang berfungsi untuk menjaga ruang dan space regainer digunakan apabila sudah terjadi penyempitan ruang. Alat ini dibedakan menjadi tipe cekat dan lepasan. ${ }^{3,4}$

Laporan kasus ini akan membahas space management kehilangan gigi posterior mandibula dengan menggunakan space maintainer semi cekat band and loop pada gigi 85 pada pasien perempuan berusia 11 tahun yang datang ke RSGM Unjani pada bulan Oktober 2018 .

\section{Laporan Kasus}

Seorang anak perempuan berusia 11 tahun datang ditemani ibunya dengan keluhan gigi belakang kanan bawah hilang karena dicabut sejak tiga bulan yang lalu. Gigi tersebut berlubang besar sehingga perlu dilakukan pencabutan. Anak tersebut merasa tidak nyaman ketika makan dan ibu pasien khawatir gigi penggantinya tidak tumbuh dengan baik.

Pemeriksaan ekstra oral, profil wajah cembung, relasi bibir kompeten, keadaan bibir normal (seperti terlihat pada Gambar 1) dan tidak ditemukan kelainan sendi temporomandibula. Pemeriksaan intra oral terlihat keadaan kebersihan mulut baik, hubungan molar kelas 1, overjet $2 \mathrm{~mm}$, overbite $2 \mathrm{~mm}$. Garis median simetris, openbite (-), cross bite (-) 
SONDE (Sound of Dentistry) Vol 5 No 2

diastema gigi $63-24,34-73,42-83,83-44,44-46$, perkembangan erupsi dalam keadaan normal.
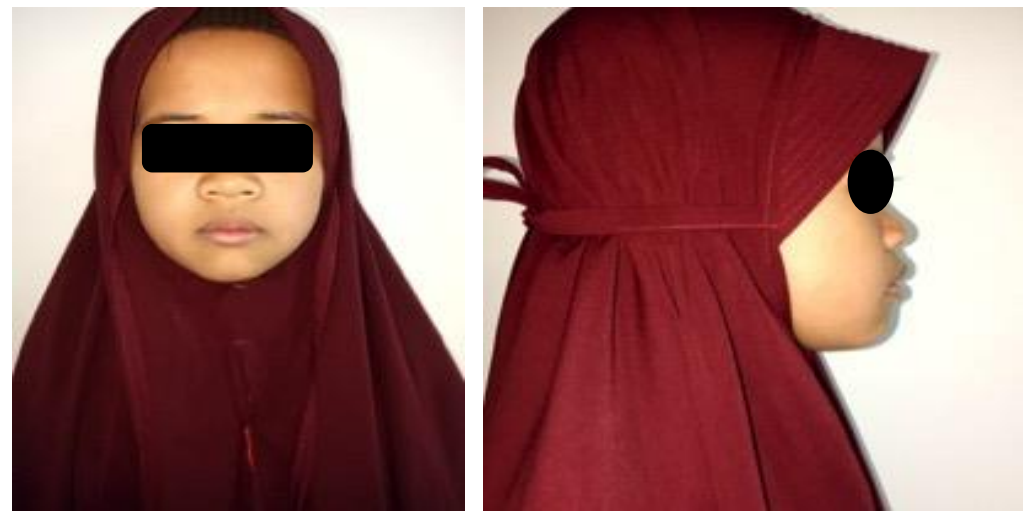

Gambar 1. Gambaran ekstra oral pasien
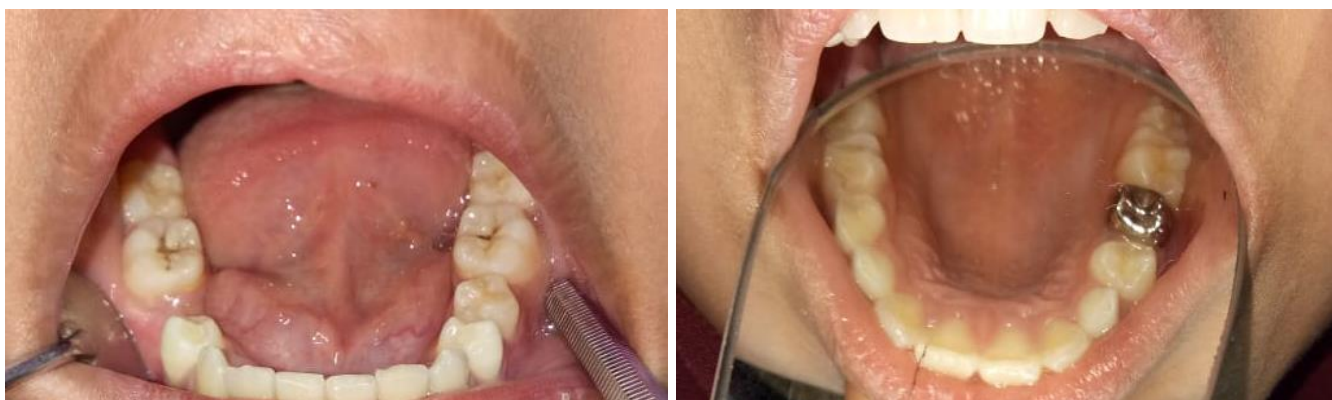

Gambar 2. Foto intra oral sebelum dilakukan perawatan
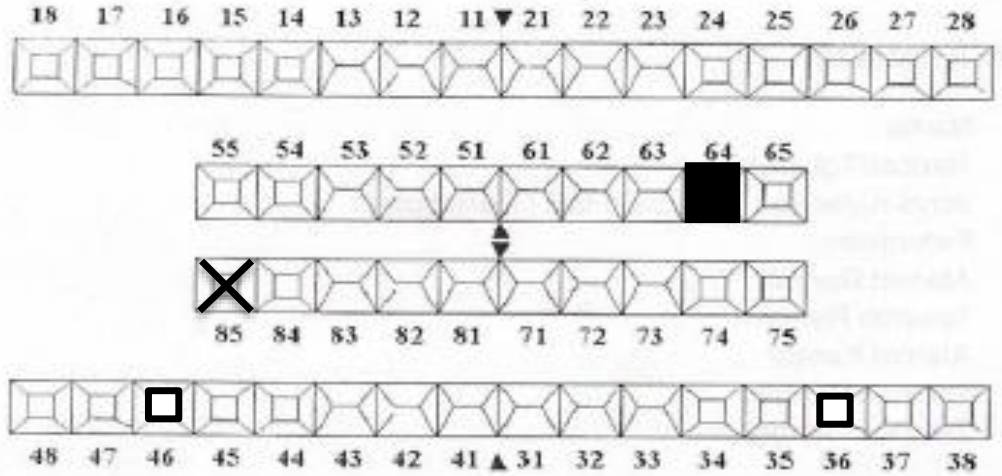

Keterangan:

Gambar 3. Odontogram

\footnotetext{
$\mathrm{X} \quad=$ Missing

$\square=$ Restorasi

$=\mathrm{SSC}$
} 


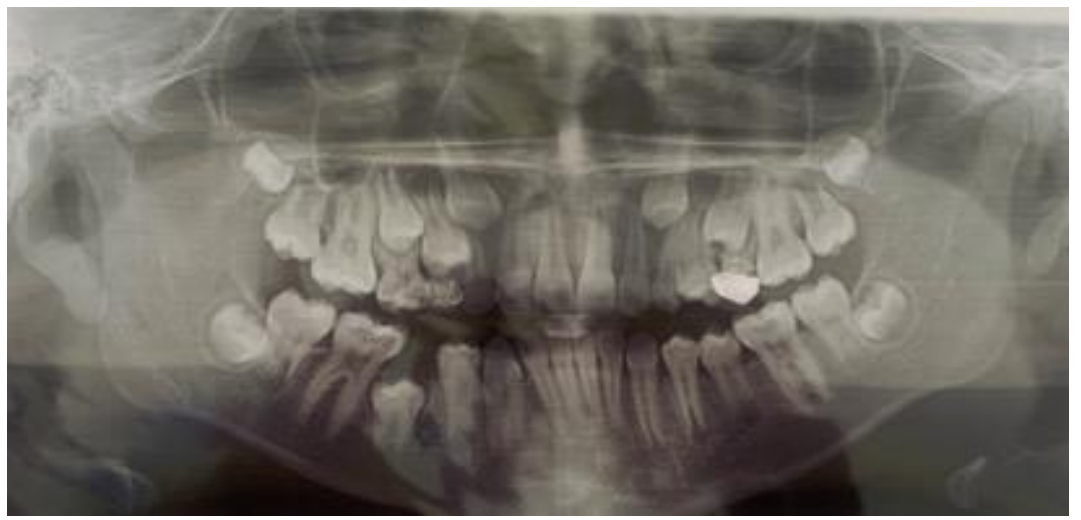

Gambar 4. Gambaran radiografi panoramik

Tabel 1. Perhitungan Moyers sebelum dilakukan perawatan space maintainer

\begin{tabular}{lccc}
\hline Gigi & $\begin{array}{c}\text { Lebar mesio distal 4 } \\
\text { anterior RB }(\mathrm{mm})\end{array}$ & $\begin{array}{c}\text { Panjang lengkung rahang } \\
\text { kiri bawah }(\mathrm{mm})\end{array}$ & $\begin{array}{c}\text { Ruang yang } \\
\text { tersedia }(\mathrm{mm})\end{array}$ \\
\hline $43,44,45$ & 21.3 & 21.5 & +0.2 \\
\hline
\end{tabular}

Perawatan yang dilakukan meliputi edukasi cara menyikat gigi dan profilaksis. Pasien dilakukan perawatan space management dengan penggunaan alat space maintainer semi cekat band and loop pada gigi untuk menjaga ruang akibat prematur loss gigi sulung. Pemberian penjelasan tentang rencana perawatan pada pasien telah disetujui orang tua pasien.

Pada pemeriksaan analisis model (Tabel 1) RB menggunakan metode Moyers, didapatkan lebar mesiodistal 4 gigi insisivus mandibula sebesar $21.3 \mathrm{~mm}$, panjang lengkung rahang kiri bawah yaitu $21.5 \mathrm{~mm}$. Berdasarkan hasil tersebut didapatkan kelebihan ruangan sebesar $+0.2 \mathrm{~mm}$ pada mandibular. Desain space management pada kasus ini berupa band pada gigi 46 untuk retensi dan loop sebagai space maintainer pada distal gigi 84.

Kunjungan pertama dilakukan Oral Hygiene Instructions (OHI) dan Komunikasi Informasi Edukasi (KIE) kepada orang tua dan anak mengenai kebersihan gigi dan mulut. Pasien diinstruksikan agar menyikat gigi dua kali sehari, pagi setelah sarapan dan malam sebelum tidur. Dilakukan mouth preparation gigi yang berlubang hingga selesai semua penambalan. 
Insersi alat space management berupa space maintainer semi cekat pada gigi 85 dengan melakukan sementasi menggunakan semen lutting GIC, sebelumnya dilakukan try-in alat space maintainer lalu memastikan loop tidak mengganggu oklusi, tidak mengenai jaringan lunak dan tidak mengganggu gigi yang akan erupsi.


Gambar 5 Uji coba space maintainer (A). Pada model kerja. (B). Saat oklusi
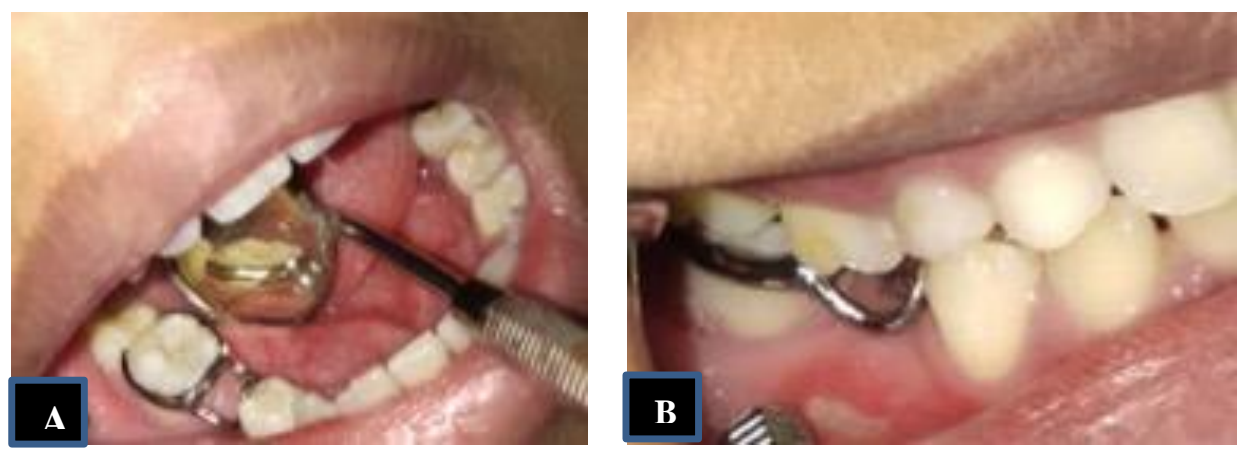

Gambar 6 Foto intra oral setelah insersi space maintainer. (A). Rahang bawah (B). Saat oklusi

Orang tua harus memastikan alat space maintainer terpasang dengan baik, tidak mengganggu jaringan sekitarnya, tidak mengganggu pengunyahan dan tidak mengganjal apabila terdapat keluhan pada alat dan jaringan sekitar, orang tua harus segera memeriksakan ke dokter gigi. Kebersihan gigi dan mulut harus tetap dijaga dan menghindari makanan yang keras dan lengket agar tidak mudah menempel pada alat. ${ }^{7-10}$ Pasien dianjurkan untuk berkumur dengan larutan yang mengandung fluoride agar mencegah terjadinya dekalsifikasi gigi di sekitar loop. Kontrol dilakukan satu minggu kemudian untuk mengontrol erupsi dari gigi pengganti. ${ }^{7,9}$ 
Kunjungan berikutnya pada tanggal 3 Desember 2018 dan 10 Desember 2018 dilakukan kontrol pada space maintainer. Setiap pasien datang kontrol dilakukan oral profilaksis, pemeriksaan keutuhan space maintainer, kondisi gigi penyangga, jaringan sekitar, oklusi dan observasi erupsi gigi pengganti. Dokter gigi selalu mengingatkan mengenai Oral Hygiene Instructions (OHI) dan Komunikasi Informasi Edukasi (KIE) kepada orang tua dan anak mengenai kebersihan gigi dan mulut. ${ }^{1}$ Kontrol rutin harus dilakukan 3 bulan sekali dan operator harus menjelaskan kepada orang tua untuk memperhatikan gigi yang akan erupsi. ${ }^{11-}$ 13
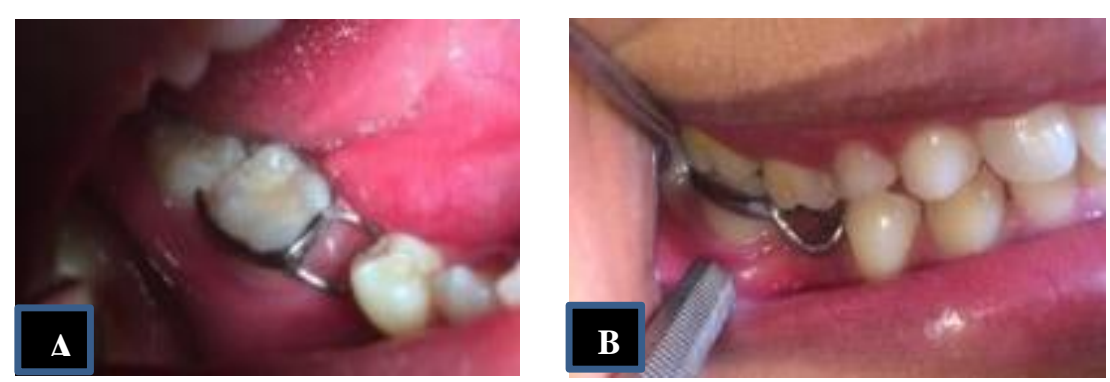

Gambar 7.(A) Foto kontrol setelah menggunakan space maintainer. (B). Saat oklusi

Kunjungan setelah insersi pada tanggal 15 November 2018 hingga kontrol pada tanggal 10 Desember 2018 belum terlihat perubahan yang signifikan pada gigi 45 yang akan erupsi. Perawatan yang dilakukan pada kasus ini masih berlanjut, kontrol dilakukan selama 3 bulan sekali atau hingga lebar ruang mesiodistal terisi oleh gigi $45{ }^{1}$

\section{PEMBAHASAN}

Terdapat tiga periode tahapan pertumbuhan gigi, yaitu periode geligi sulung, periode geligi campuran dan periode geligi permanen. Erupsi geligi sulung pertama yang muncul adalah dua gigi bawah bagian depan atau insisif satu. Waktu erupsi geligi sulung umumnya bervariasi, begitu juga dengan lebar mesio distal dari geligi sulung., ${ }^{5,6}$

Prematur loss gigi sulung dapat menyebabkan penyempitan ruang. Penyempitan ini terjadi karena pergeseran gigi sebelahnya. Hal ini terjadi karena sifat gigi akan mengisi ruang kosong di sebelahnya. Pergeseran ini akan mengganggu erupsi gigi permanen di bawahnya. Hal ini dapat mengakibatkan gigi permanen akan erupsi dalam posisi yang tdk menguntungkan. Akibatnya susunan gigi geligi menjadi tidak rapi dan pada beberapa kasus, 
hal ini akan menyebabkan terjadinya gigi berjejal (crowding), maka dibutuhkan perawatan lebih lanjut yang disebut space management. ${ }^{6,7}$

Space management terdiri dari space maintainer dan space regainer. Space maintainer merupakan suatu alat yang digunakan untuk mempertahankan lebar mesio-distal akibat kehilangan gigi sulung secara dini dan mempertahankan kontak oklusal yang cukup untuk gigi antagonisnya yang diperlukan sampai gigi permanen erupsi sempurna. ${ }^{4,8,9}$

Indikasi dari space maintainer adalah:

1. Kehilangan gigi molar pertama sulung secara dini

2. Kehilangan gigi molar kedua sulung secara dini

3. Kehilangan gigi anterior sulung secara dini

4. Kehilangan gigi secara kongenital

5. Setelah dilakukan pencabutan gigi molar pertama dewasa.

6. Apabila terjadi kehilangan gigi sulung dan gigi penggantinya belum siap erupsi menggantikan posisi gigi sulung tersebut dan analisa ruang menyatakan masih terdapat ruang yang memungkinkan untuk gigi permanen.

7. Jika terdapat kebiasaan buruk pada anak, contohnya menempatkan lidah di daerah yang tidak bergigi atau menghisap bibir maka pemasangan space maintainer ini dapat menjadi indikasi untuk menghilangkan kebiasaan buruk.

8. Kebersihan mulut baik.

Pengunaan space maintainer harus memenuhi syarat agar dapat menjaga kesehatan jaringan sekitarnya, diantaranya tidak menggangu erupsi gigi antagonis dan erupsi gigi permanen, tidak memengaruhi fungsi bicara, pengunyahan, dan fungsi pergerakan mandibula, harus dapat mencegah ekstrusi gigi antagonis tetapi tidak menyebabkan traumatik oklusi, serta tidak mengganggu jaringan lunak, tidak memberikan tekanan berlebih pada gigi penyangga, desain sesederhana mungkin, ekonomis, mudah untuk dibersihkan dan dapat menjaga ruang dimensi proksimal. ${ }^{1,7,8}$

Ada beberapa jenis space maintainer yang dapat digunakan dalam bidang kedokteran gigi, klasifikasi space maintainer berdasarkan adanya anchorage dan support, diantaranya: ${ }^{1,7}$ 


\section{Space Maintainer Semi Cekat}

a. Crown-distal shoe space maintainer

Space maintainer ini diindikasikan untuk menjaga ruang akibat kehilangan gigi molar kedua sulung, sementara itu crown diindikasikan untuk gigi dengan karies yang luas., 1,7,9.
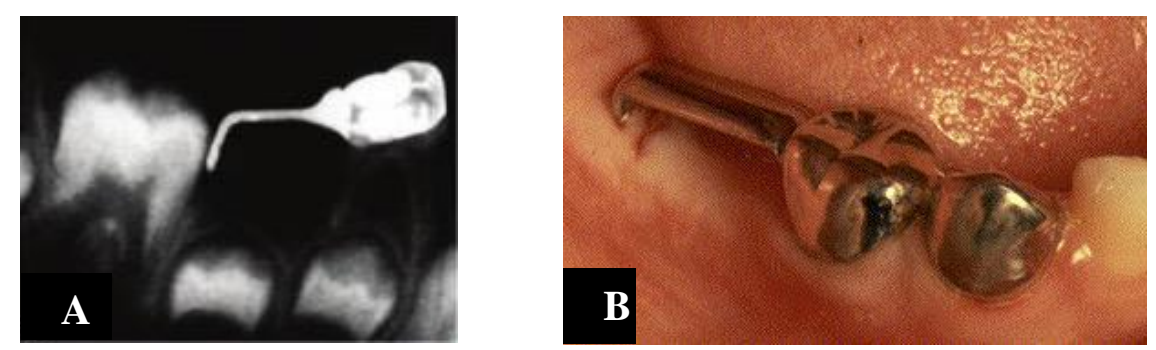

Gambar 8 (A). Space maintainer crown distal shoe dilihat pada foto rontgen; (B) Space maintainer crown-distal shoe ${ }^{l}$

\section{b. Crown and loop space maintainer}

Space maintainer crown-loop dapat digunakan pada gigi di maksila maupun mandibula dengan gigi penyangga dalam keadaan karies yang luas sehingga dibutuhkan restorasi (crown). Space maintainer ini biasanya digunakan untuk menjaga kehilangan satu gigi. ${ }^{1,7}$

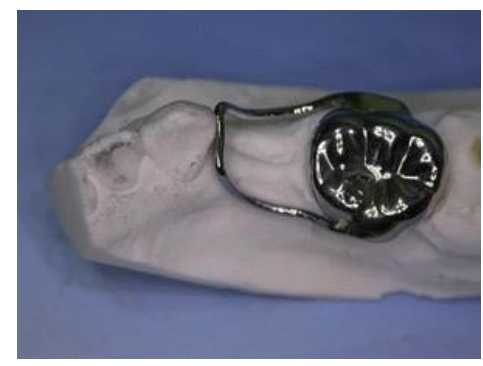

Gambar 9 Crown- loop space maintainer ${ }^{1}$

\section{c. Band and loop space maintainer}

Space maintainer band-loop dapat digunakan pada gigi di maksila maupun mandibula dengan gigi penyangga dalam keadaan sehat. Space maintainer ini biasanya digunakan untuk menjaga kehilangan satu gigi. ${ }^{1,7,9}$ 


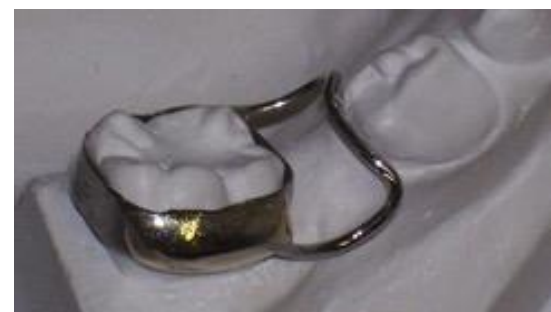

Gambar 10 Space maintainer band-loop ${ }^{1}$

\section{Space Maintainer Cekat}

a. Lingual-holding-arch space maintainer

Space maintainer ini diindikasikan untuk premature loss gigi posterior dan dapat menghilangkan kebiasaan buruk. Estetika sangat baik karena wire berada pada lingual. ${ }^{1,9,10}$

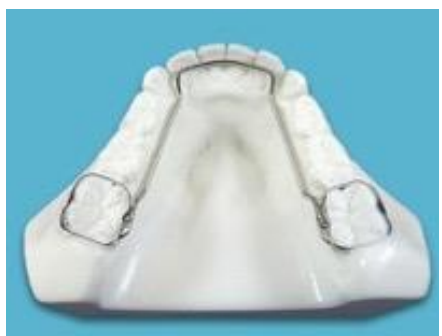

Gambar 11 Space maintainer lingual arch ${ }^{1}$

b. Nance's holding arch

Space maintainer ini hanya digunakan pada maksila dengan kehilangan gigi posterior yang multiple pada kedua sisi dan dapat digunakan untuk menghilangkan kebiasaan buruk. Space maintainer Nance's holding arch dibuat dengan menggunakan wire yang dihubungkan dengan akrilik dan band pada M1 pemanen. ${ }^{1,9,10}$

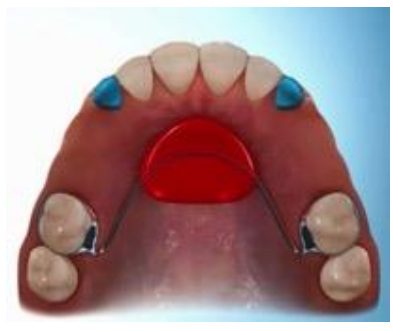

Gambar 12. Space maintainer nance palatal $\operatorname{arch}^{1}$ 


\section{Removable space maintainer}

a. Non-functional space maintainer

Space maintainer non-fungsional ini mempunyai fungsi sama dengan space maintainer fungsional. Daerah edentulous pada space maintainer ini tidak ditambahkan gigi artifisial melainkan diisi dengan akrilik. ${ }^{1,11,12}$

\section{b. Functional space maintainer}

Alat ini digunakan khusus bila gigi hilang dalam satu kuadran atau lebih pada rahang atas maupun rahang bawah. Alat ini dapat ditambahkan gigi artifisial untuk mengembalikan fungsi estetik. ${ }^{1,11,12}$
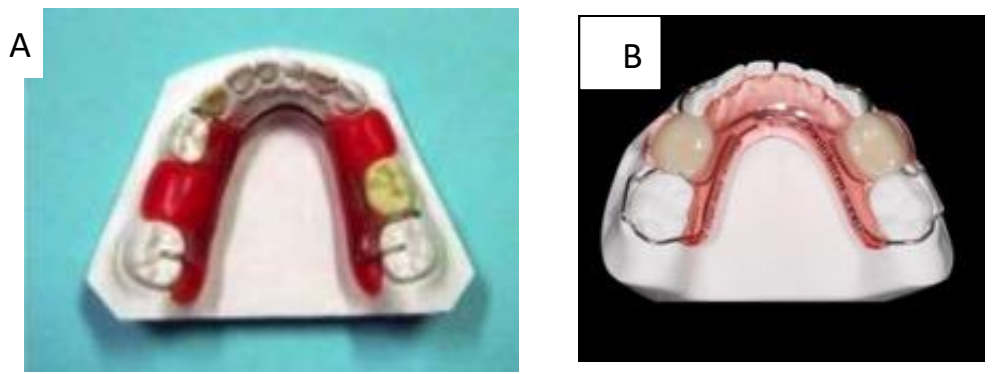

Gambar 13. (A) Space maintainer bilateral lepasan pasif non-fungsional (B) Space maintainer bilateral lepasan pasif fungsional

Pada kasus ini premature loss terjadi pada gigi 85. Premature loss pada gigi tersebut disebabkan oleh karies. Dampak yang ditimbulkan dari premature loss berupa perubahan panjang lengkung gigi dan oklusal. Besar dan kecepatan pergeseran gigi berhubungan langsung dengan derajat crowding pada lengkung gigi. ${ }^{7,8}$

Maloklusi dapat terjadi setelah premature loss karena kebiasaan anak menempatkan rahangnya pada posisi yang abnormal untuk mendapatkan fungsi oklusi dan pengunyahan yang baik. Geligi tersebut mungkin akhirnya menjadi abnormal secara tetap baik dalam hubungan ke depan maupun ke lateral. ${ }^{10,11}$

Dampak yang ditimbulkan pada premature loss adalah gangguan artikulasi pada pengucapan huruf konsonan s,z,v,f. Premature loss gigi sulung baik di regio anterior 
maupun posterior sangat memungkinkan terjadinya pergerakan oleh lidah ke tempat ruangan kosong. Kebiasaan yang terus-menerus ini dapat menyebabkan malposisi pada gigi pengganti tergantung pada banyaknya tekanan dari lidah. ${ }^{10,12}$

Premature loss gigi 85 pada kasus ini dilakukan koreksi dengan menggunakan alat space management berupa space maintainer semi cekat yaitu band and loop untuk mempertahankan ruangan yang hanya kehilangan satu gigi saja. Fungsi dari space maintainer ini adalah untuk mencegah pergeseran pada gigi ke ruangan kosong yang terjadi akibat dari premature extraction, mencegah ekstrusi gigi antagonis dari gigi yang mengalami premature extraction, meminimalisasi maloklusi, memperbaiki fungsi pengunyahan anak dan mengembalikan kesehatan gigi yang optimal, memperbaiki fungsi estetik dan fonetik. ${ }^{7,8}$ Pemilihan rencana perawatan space management didasarkan pada perkembangan gigi, jumlah gigi yang hilang, oklusi, lengkung rahang, usia pasien, kondisi psikologis, dan tingkat kooperatif pasien. ${ }^{13-15}$

Saat kontrol dilakukan pengecekan sementasi pada space maintainer semi cekat band and loop, kesehatan jaringan sekitar, oklusi, retensi dan observasi gigi permanen penggantinya. Perawatan yang dilakukan pada kasus ini masih berlanjut, kontrol selama 3 bulan sekali atau hingga lebar ruang mesiodistal terisi oleh gigi 45 sehingga dapat mengembalikan masalah fungsional, estetik, dan stabilitas di dalam rongga mulut.

\section{Simpulan}

Kelainan oklusi yang terjadi lebih lanjut pada proses tumbuh kembang anak dapat dicegah dengan menggunakan alat khusus untuk menjaga ruang akibat premature loss, salah satunya yaitu space maintainer semi cekat band and loop. Alat ini dipasang pada daerah tak bergigi.

Pada kasus ini dilakukan perawatan space maintainer semi cekat pada gigi 85 dengan hasil yang memuaskan. Ruang yang ada dapat terjaga dengan baik. 


\section{Daftar Pustaka}

1. Mc Donald RE, Hennon DK, Avery DR. Managing space problem: In Dentistry for the children and adolescent. $5^{\text {th }}$ Ed. Maw Chang Book. 1987. p.721-726.

2. Sigh G. Textbook of orthodontics. $2^{\text {nd }}$ Edition. New Delhi: Jaypee Brothers Medical Publishers. 2015. p.563-571.

3. Suwendra VS. Principlces and practice of pedodontics. $3^{\text {rd }}$ Edition. New Delhi: Jaypee Brothers Medical Publishers. 2012. p.156-159.

4. Kennedy DB. Konservasi gigi anak. Translate: Narlan S, Sri HS. Edisi 3. Jakarta. 1992. hal.1-10.

5. Sweet CA. Pedodontics in grossman LI. Handbook of dental practice. $3^{\text {th }}$ Ed. Philadelphia: JB Lippincott. 2009. p.379-421.

6. Snawder KD. Handbook of clinical pedodontics. London: The CV Mosby. 1980. p.259-75.

7. Welbury R R, Duggal M S, Hosey M T. Paediatric dentistry. $3^{\text {rd }}$ Edition. New York: Oxford Univesity Press; 2005.

8. Behrman RE, dkk. Nelson ilmu kesehatan anak: translation of nelson textbook of pediatrics. Alih Bahasa: Prof.DR.dr.A.Samik Wahab,SpA(K). Jakarta: EGC; 2000.

9. Cameron AC, Widmer RP. Handbook of pediatric dentistry. Third Edition. London: Mosby Company; 2008.

10. Heasman P. Restorative dentistry: pediatric dentistry and orthodontics. Second Edition. New York: Churchill Livingstone Elsevier; 2008.

11. Muthu MS, Sirakumar N. Pediatric dentistry: principle and practice. $1^{\text {st }}$ Edition. New Delhi: Mosby Saunders, Churchill Livingstone. 2009. p.315317.

12. Wibowo, Teguh Budi dan Nuraini, Pratiwi. 2008. Pediatrict space management. at http://isjd.pdii.lipi.go.id/admin/jurnal/2320897101.pdf [3 Maret 2018].

13. Aztecortholab. 2002. Space regainer and space regainer laboratory.retrived at http://www.aztecortholab.com/appliances.html

14. Cameron C Angus and Richard P Widmer.2003. Handbook of Pediatric Dentistry Second Edition. Mosby Elsevier. China.

15. Omar A. Bawazir. 2009. Evaluation of Space Mainteiners Febricated by Dental Students : A Retrospective Study. Pakistan Oral \& Dental Journal Vol 29, No. 2 (December 2009) 